\title{
Crítica de mídia em perspectiva aberta ${ }^{1}$
}

\section{Broad perspectives for media critique}

\author{
José Luiz Aidar Prado²
}

Uma primeira versão deste trabalho foi apresentada no I Simpósio de crítica de mídia: Como criticam os que criticam, realizado em 21 e 22 de setembro de 2017 na Universidade Federal de Santa Catarina (UFSC).

2 Professor do Programa de Estudos Pós-graduados em Comunicação e Semiótica da Pontifícia Universidade Católica de São Paulo (PUC-SP). É autor de Habermas com Lacan (EDUC, 2015) e Convocações biopolíticas nos dispositivos comunicacionais (EDUC, FAPESP, 2013) e coautor de Sintoma e fantasia no capitalismo comunicacional (Estação das Letras, 2017). É editor da revista Galáxia. E-mail: aidarprado@gmail.com. 


\section{Resumo}

O que significa hoje fazer crítica midiática? Abordaremos o tema em duas vetorizações: a primeira entendendo a crítica a partir de Judith Butler; a segunda situando o midiático da crítica a partir da psicanálise, considerando os conceitos de sintoma e fantasia. Como objeto concreto, examinaremos o tema da polarização pós-2013 no país a partir da questão dos afetos. Como dar conta dessa polarização? Como a teoria do discurso, a psicanálise e a semiótica tensiva podem colaborar na tarefa de situar essa polarização a partir da política e do circuito dos afetos?

\section{Palavras-chave}

Crítica midiática, psicanálise, política, afetos.

\section{Abstract}

What does it mean to criticize media nowadays? We will discuss this theme in two directions: first, conceptualizing critique by using Judith Butler; then, we will conceptualize the mediatic part from the critique, from the perspective of psychoanalysis, considering the concepts of symptom and fantasy. Concretely, we will examine the polarization in Brazil after 2013, from the idea of affections. How to deal with this polarization? How can discourse theory, psychoanalysis and tensive semiotics collaborate to situate this polarization from politics and the circuit of affections?

\section{Keywords}

Media critique, psychoanalysis, politics, affects. 
Abordaremos a crítica midiática em perspectiva aberta, a partir de três temas: primeiro, o que é, hoje, crítica?; segundo, como fazer crítica midiática, pensando aí o texto e o contexto, em termos de regimes de programação neoliberais, numa situação de convergência e hibridização; e terceiro, por que a perspectiva da crítica deveria ser aberta. De que abertura se trata?

Vamos ao primeiro ponto: a crítica hoje. Butler (2005) retoma o tema da crítica principalmente a partir de Foucault, com a pergunta: o que significa oferecer uma crítica? A crítica não deve flutuar acima do mundo, das práticas mundanas, endeusada e abstrata, olhando o panorama econômico e cultural de cima para baixo, mas deve ser dirigida concretamente a práticas, discursos, epistemes e instituições, e perde seu caráter no momento em que é abstraída de sua operação e feita para se sustentar sozinha, como uma generalização. Ela não deve estar descolada de práticas concretas, das disputas e dos conflitos políticos no meio do mundo. Não deve, portanto, ser enunciada como um julgamento, mas deve oferecer novas perspectivas com práticas de valores ligados a lutas concretas, encarando os antagonismos específicos. A crítica deveria, nessa visão, funcionar mais como um cinto de utilidades, como um painel de supervivência na selva e não só de sobrevivência.

Isso lembra a crítica de Badiou ao homem-vítima. Para Badiou (1994), o homem que sobrevive é a vítima, e é preciso sair desse estado. Em outras palavras, não se trata de construir uma teoria normativa forte, que trace diretrizes e planos a partir de julgamentos, mas de abraçar modos concretos de avaliar práticas "em termos de habilidades de alcançar objetivos" (BUTLER, 2005, p. 307). Trata-se, ao fim e ao cabo, de objetivos políticos, para mudar as coordenadas das situações na direção de um mundo mais democrático, num contexto que poderíamos chamar hoje de pós-democrático. Por que pós-democrático? Porque, como dizem Lazzarato e Alliez (2016), 
declaram guerra ao estrangeiro, ao imigrante, ao muçulmano e às camadas mais pobres, para o único proveito das direitas extremas "desdiabolizadas". São estas últimas que voltam a instalar-se no terreno das guerras civis que elas conseguem subjetivar por meio do reinício de uma guerra racial de classe. A hegemonia neofascista sobre os processos de subjetivação ainda é confirmada pela retomada da guerra contra a autonomia das mulheres e dos devires-menores da sexualidade.

A crítica deve ser pensada nesse contexto de guerras espalhadas, de guerras culturais, polarizadas, estabelecidas contra os imigrantes e minorias, e contra programas de redistribuição, sempre atravessando a economia política e a crítica do Estado. Cultura e economia estão intrincadamente solidárias no capitalismo comunicacional atual.

No seminário Nascimento da Biopolítica, Foucault (2008) fala sobre o método que utiliza para investigar o neoliberalismo, através da genealogia dos regimes de veridicção. Para ele, a opção de fazer a história desses regimes implica em "recusar fazer a crítica da racionalidade europeia, do romantismo à Escola de Frankfurt. Não se trata de fazer a crítica da parte opressiva da razão, porque a desrazão é igualmente opressiva" (FOUCAULT, 2008, p. 49). A crítica que ele propõe está em "determinar em que condições e com quais efeitos se exerce uma veridicção, isto é, mais uma vez, um tipo de formulação do âmbito de certas regras de veridicção e de falsificação" (FOUCAULT, 2008, p. 50). Não se trata de dizer, afirma Foucault, "vejam como a psiquiatria é opressiva, já que é falsa", ou "olhem como é opressiva, já que é verdadeira" (FOUCAULT, 2008, p. 50). O que ele quer é

trazer à luz as condições que tiveram de ser preenchidas para que se tivessem de emitir sobre a loucura, delinquência, sexo os discursos que podem ser verdadeiros ou falsos de acordo com as regras que são as da medicina ou as da confissão ou as da psicologia, ou as da psicanálise. (FOUCAULT, 2008, p. 50)

A crítica depende, portanto, dos objetos com os quais ela se relaciona, e tem de estar atenta para a estrutura de sua própria avaliação, como diz Butler, a partir de Foucault. A pergunta que ela nos lança é: "qual é a relação de nosso 
conhecimento ao poder de modo que nossas certezas epistemológicas apoiam um modo de estruturar o mundo que suprime (foraclui) possibilidades alternativas de ordenação"? (BUTLER, 2005, p. 307). Para responder a isso em cada caso, na relação com objetos concretos, é preciso saber como o capitalismo neoliberal vem promovendo enquadramentos no cotidiano de sujeitos e instituições.

\section{O ambiente midiático no neoliberalismo}

O segundo aspecto do presente texto busca situar o midiático da crítica. Aqui abordaremos vários aspectos. Primeiro, vivemos na era da convergência das mídias. O tema já está repisado - e esse conceito deve ser criticado também -, mas é importante evocá-lo aqui, pois os discursos circulam rapidamente em várias plataformas e recebem respostas e acréscimos de vários interlocutores, nem sempre com argumentos sustentados e sustentáveis, mas que criam públicos de agregados, de aderentes, formando bolhas de posições diversas. Não basta examinar um texto que esses discursos atravessam. É preciso pensar os acontecimentos em sua travessia de plataformas, para mapear posições formadas nesse rastro, nessa travessia.

Assim sendo, aspecto importante da crítica midiática hoje se dá em decorrência dessa atividade de alta circulação e espalhamento de discursos e de posições frente a eles, exigindo cuidado na análise da relação entre texto e contexto. O texto é um momento dessa circulação, e a análise discursiva ou semiótica deve ter clareza dessa relação entre texto e contextos, e da forte intertextualidade daí decorrente. Especialmente, em termos de relação com os contextos, é preciso dar conta da forte presença da economia nos mundos culturais, a partir dos programas neoliberais.

Como diz Wendy Brown, o neoliberalismo não é somente um conjunto de políticas econômicas, uma fase do capitalismo ou a ideologia que liberta o mercado para que se recupere o lucro da classe capitalista, mas uma ordem de razão normativa, estendendo uma formulação específica de valores, práticas e métricas a todas as dimensões da vida, e não somente à econômica (BROWN, 2017, p. 93). Essa racionalidade "refaz, em termos econômicos, a forma, o conteúdo e 
a conduta de domínios até agora não econômicos" (BROWN, 2017, p. 93). Essa economicização não envolve sempre monetização: a economicização "implacável e ubíqua de todas as características da vida pelo neoliberalismo não significa que ele marquetize literalmente todas as esferas" (BROWN, 2017, p. 93), mas que ele dissemine "um modelo do mercado para todos os domínios e atividades que configuram os seres humanos exaustivamente como atores do mercado, em todo lugar e apenas como homo economicus" (BROWN, 2017, p. 93).

E quem é hoje o homo economicus? Não é mais o mercador que busca sem cessar seus interesses, ou o utilitarista clássico que quer minimizar dor e aumentar o prazer; seu projeto hoje é

auto-investir e atrair investidores, de modos que melhorem sua taxa real ou figurativa de crédito e capitalizem seu eu e seu patrimônio, seja através de seguidores das mídias sociais, likes, retweets, através de rankings e avaliações para todas as atividades e domínios, ou através de práticas mais diretamente monetizadas (BROWN, 2017, p. 94).

Há, portanto, uma economicização dos sujeitos. Nesse sentido, Brown vê três diferenças principais em relação ao liberalismo anterior: a) somos somente e em todos os lugares homo economicus; b) este toma forma como capital humano (cujo imperativo é o de fortalecer seu posicionamento competitivo), mais que como figura da troca ou do interesse; c) o modelo atual específico de capital humano é o do capital financeiro e não do produtivo. Assim, cada vez mais,

homo oeconomicus como capital humano se refere a melhorar seu valor de portfolio em todos os domínios da vida, uma atividade voltada a práticas de auto-investimento e atração de investidores. Consumo, educação, treinamento, lazer, seleção de parceiros, são configurados como decisões sobre o auto-investimento relativo a melhorar seu valor futuro. Isso também torna tanto o projeto e a apropriação do ethos e da conduta do capital humano indistinguíveis daqueles de todos os capitais financeiros hoje (BROWN, 2017, p. 95). 
Como consequência da construção e do espalhamento desse tipo de conduta, altera-se radicalmente a configuração da esfera política, com a transposição dos "princípios políticos democráticos de justiça para o idioma econômico" (BROWN, 2017, p. 95). O Estado se transforma num gestor da nação, e se esvaziam a cidadania democrática e a soberania popular. Por essa razão, falamos anteriormente na pós-democracia liberal, espécie de estado de exceção e de guerra cultural em que os antagonismos não se resolvem em lógicas equivalenciais - para lembrar a lógica da equivalência, de Laclau (2015) - , mas estabelecem condomínios culturais que ficam em guerra permanente com a alteridade discursiva.

Para dar conta desses aspectos dos programas neoliberais, adotamos, em outro texto (PRADO, 2017a), a perspectiva da psicanálise, com os conceitos de sintoma e fantasia. Vimos em trabalhos anteriores (PRADO, 2011, 2013) o papel das interpelações e convocações midiáticas nos contratos de comunicação que visam propor modalizações aos consumidores ativos. Buscamos os pontos sintomáticos do capitalismo comunicacional a partir de temas como sustentabilidade, gourmetização e cultura nerd, entre outros (PRADO, 2017b). Falar em sintoma implica estar atento para a inversão que o enunciador promove de modo a positivar a negatividade de um discurso como o ambientalismo, por exemplo. Lá onde esse discurso critica o funcionamento do capital, o enunciador liberal capitalista instala sua máquina prestidigitadora e faz tamponamento com sua rolha da sustentabilidade, que sutura o furo em que poderia entrar a faca do discurso ambientalista (PRADO, 2015, 2017a, 2017b). Faca vira rolha na inversão sintomal. Rolha espetacular, que dá brilho lá onde haveria tempestade. Em outras palavras, a sustentabilidade é um sintoma no liberal capitalismo.

A localização de sintomas é apenas o primeiro passo para a crítica. Há também um passo posterior, o desmonte da fantasia, que cria a cena do gozo. Aqui os objetos de consumo são colocados como elementos de fantasias dentro de regimes de programação ligados à construção do capital do eu s/a. A fantasia canaliza o gozo e o afeto, transformando-o a partir das coordenadas de prazer, mas sempre há resto que atrapalha a completude esperada (PRADO, 2017a). 


\section{Polarização}

Em nossa pesquisa atual, temos examinado o tema da polarização pós2013 no país a partir da questão dos afetos. Como dar conta dessa polarização? Partimos da ideia de que junho de 2013 foi um acontecimento, pelo menos até dia 17, e a polarização se estabeleceu mais fortemente principalmente nos anos seguintes, especialmente na época do impeachment. Buscamos interrogar as mídias hegemônicas e os posts do Facebook de grupos à direita e à esquerda do espectro político. Hoje, deixaremos de lado as mídias hegemônicas e nos concentraremos em alguns desses grupos no Facebook.

Angela Alonso (2016) propôs três ciclos de protestos desde 2013. O primeiro ocorreu em junho de 2013 - a cena é um "mosaico de pequenos movimentos independentes, distribuídos em dois grandes campos", o dos grupos autonomistas e o dos socialistas, dentro das esquerdas. Segundo a pesquisadora, os primeiros fizeram protestos 'performáticos', trabalharam o horizontalismo, a estética anarquista e os símbolos da justiça global. Os movimentos sociais de viés socialista defendiam a redistribuição, com uma organização mais tradicional, verticalizada, com bandeiras vermelhas e símbolos conhecidos da luta política de esquerda. Há aí demandas por "expansão e melhora de políticas sociais, transporte e saúde, educação".

Há aí nesse grupo um discurso que vê na democracia a possibilidade de troca de experiências entre diferentes grupos e um equilíbrio entre diferença e igualdade, em que, numa mesa de discussões, sentam diferentes enunciadores com conhecimentos diversos. Isso lembra a ecologia de saberes em Boaventura Santos (2006, 2007) ou a semiótica da mistura, de Zilberberg e Fontanille (2001). Voltaremos a isso.

Contra esses dois grupos à esquerda, emergiu um terceiro, à direita, caracterizado por

um campo de manifestantes independentes, sem coordenação ou experiência política, atraídos pela internet ou pelo noticiário. Mais expressivo do que propositivo, içou a bandeira nacional. Cartazes, roupas, 
pinturas faciais recuperaram os símbolos nacionalistas pelos movimentos pela redemocratização e pelo impeachment de Collor (ALONSO, 2016).

Essa direita se vestiu de verde e amarelo e declarou ódio ao PT, e se reuniu em torno do significante "corrupção", como se o pemedebismo não fosse o sistema, por excelência, da fisiologia desde os anos 1990. Aqui, portanto, temos mais uma semiótica da triagem e não da mistura.

Nesse front com figuração de "patriota", havia críticas à hipertrofia e ineficiência do Estado, aos políticos e à retomada da divisa do Fora Collor: "ética na política". O campo "apatriotado"3 ganhou volume em 2014, enquanto os dois outros campos "esmaeciam". Três movimentos lideraram os "apatriotados": o liberal Vem para a rua, o Movimento Brasil Livre, mais à direita, e, no extremo, o Revoltados ON LINE.

Um segundo ciclo começou em março de 2015, afirma Alonso (2016), em que "54 grupos similares se albergaram na Aliança Nacional dos Movimentos Democráticos, fincada em estados tucanos, sobretudo São Paulo, e com suporte do empresariado" (ALONSO, 2016). As manifestações se ampliaram ao redor do discurso anti-Dilma e anti-PT, na defesa do impeachment, contestação esta "expressa em retórica moralizadora de dois sentidos: a afirmação da moralidade pública (anticorrupção) e o moralismo, reiteração de valores da sociedade tradicional (como pátria, religião, família), óbvios nos atos encerrados com rezas e hino nacional" (ALONSO, 2016). O novo herói da pátria colorida é Moro.

O terceiro ciclo ocorreu mais próximo do impeachment, em 2016:

persistiram os patriotas, hibernaram os autonomistas, acordaram os socialistas. Os aliados do PT, os sindicatos, e duas novas coalisões, a Frente Povo sem Medo (cerca de 30 movimentos) e a Frente Brasil Popular (com mais de 70 organizações), recuperaram a pauta petista dos anos 1980 : defesa do estado de direito ('não vai ter golpe'), pró-políticas sociais e combate ao oligopólio dos meios de comunicação ('o povo não é bobo, abaixo a Rede Globo')". Nessa direção se construíram os atos contra o impeachment, e "em desagravo a Lula" (ALONSO, 2016). 
A multiplicidade de 2013 se polarizou em 2015 e 2016 em dois campos: um anti-PT e outro contra o golpe. "A cerca invisível de 2013 virou muro de concreto nas votações do impeachment na Câmara e no Senado" (ALONSO, 2016). O acontecimento de 2013, na medida em que vários grupos foram tentando dar sentido a ele, foi sendo disputado e apropriado pelos discursos e perdendo a intensidade inicial, crescendo as totalizações da direita, que canalizaram a inicial pressão da multidão em confronto contra o governo federal, em discursos anticorrupção, discursos de responsabilidade econômica (corte de gastos, mudança de regras previdenciárias) e de apologia a valores tradicionais. Ao mesmo tempo, as instituições começaram inúmeras ações contra o PT a partir do judiciário e da mídia hegemônica.

A ideia central da pesquisa é perpassar vários textos, tanto da mídia hegemônica, quanto de posts do Facebook, quanto de mídias alternativas, a fim de investigar como a polarização entre movimentos à esquerda e à direita se constituiu a partir do acontecimento inicial de 2013. Alguns resultados desse trabalho estão apresentados em Prado (2018) e Prado e Prates (2017a).

\section{A crítica}

Nossa questão no presente texto é: como realizar a crítica a partir daí? Consideraremos cinco itens principais:

1. É preciso restabelecer o quadro, o enquadramento; no caso, o da polarização. A polarização enquadra os temas ligados ao reconhecimento como perspectivas de esquerda, que devem ser combatidas, e não se admite mais a argumentação com base nas demandas de reconhecimento, porque elas são esvaziadas por serem lidas, antes de tudo, como de esquerda. O quadro polarizador rotula para esvaziar o debate democrático, reforçando a política neoliberal.

2. A partir desse quadro, quais são as posições de sujeito (cf. LACLAU, 2013; HOWARTH; STAVRAKAKIS, 2000) construídas pelos discursos na posteridade do acontecimento de 2013? Aqui, utilizamos o conceito de 
acontecimento de Badiou (1996) e de Zilberberg (2011), já tratado em textos anteriores (PRADO, 2013b, 2015, 2016a, 2016b, 2017a, 2017c). Como se dá a dinâmica de antagonismos discursivos no pós-acontecimento?

3. Quais os contratos de comunicação aí estabelecidos, em diferentes textos, tanto das mídias hegemônicas quanto alternativas e de posts dos vários movimentos, tanto à direita como à esquerda, no Facebook? Os contratos são interpelativos e convocam os destinatários para vários programas, ditados a partir de regimes de interação e visibilidade (cf. PRADO, 2013a).

4. Entre 2013 e 2016, marcamos vários pontos temporais ligados a fatos que assumem importância na construção da polarização. Para cada um desses eventos (que não trataremos como acontecimentos) haverá uma coleta de textos e uma análise discursiva. Ela não se reduz à análise de cada texto, mas remete ao quadro maior de circulação das posições antagonistas: que pontos nodais costuram as totalizações discursivas provisórias?

5. Finalmente, como ler o circuito dos afetos ligado a esse quadro geral de polarização que se constrói de 2013 a 2016? Aqui a semiótica tensiva e a psicanálise darão auxílio fundamental. A primeira, a partir dos conceitos de semiótica da mistura e da triagem (ZILBERBERG; FONTANILLE, 2001), como dissemos anteriormente. A segunda, a partir do conceito de gozo e das teorizações da esquerda lacaniana (FONTENELLE，2013, 2017; NASIO, 1993; ZIZEK, 2013, 2014; ZUPANCIC, 2017).

Abordaremos agora, com mais vagar, esse quinto item. Zilberberg e Fontanille (2001) afirmam que a articulação do valor a partir dos eixos da intensidade e da extensidade se dá a partir dos operadores da triagem e da mistura (extensidade), e dos operadores da tonicidade e da atonicidade (intensidade). 


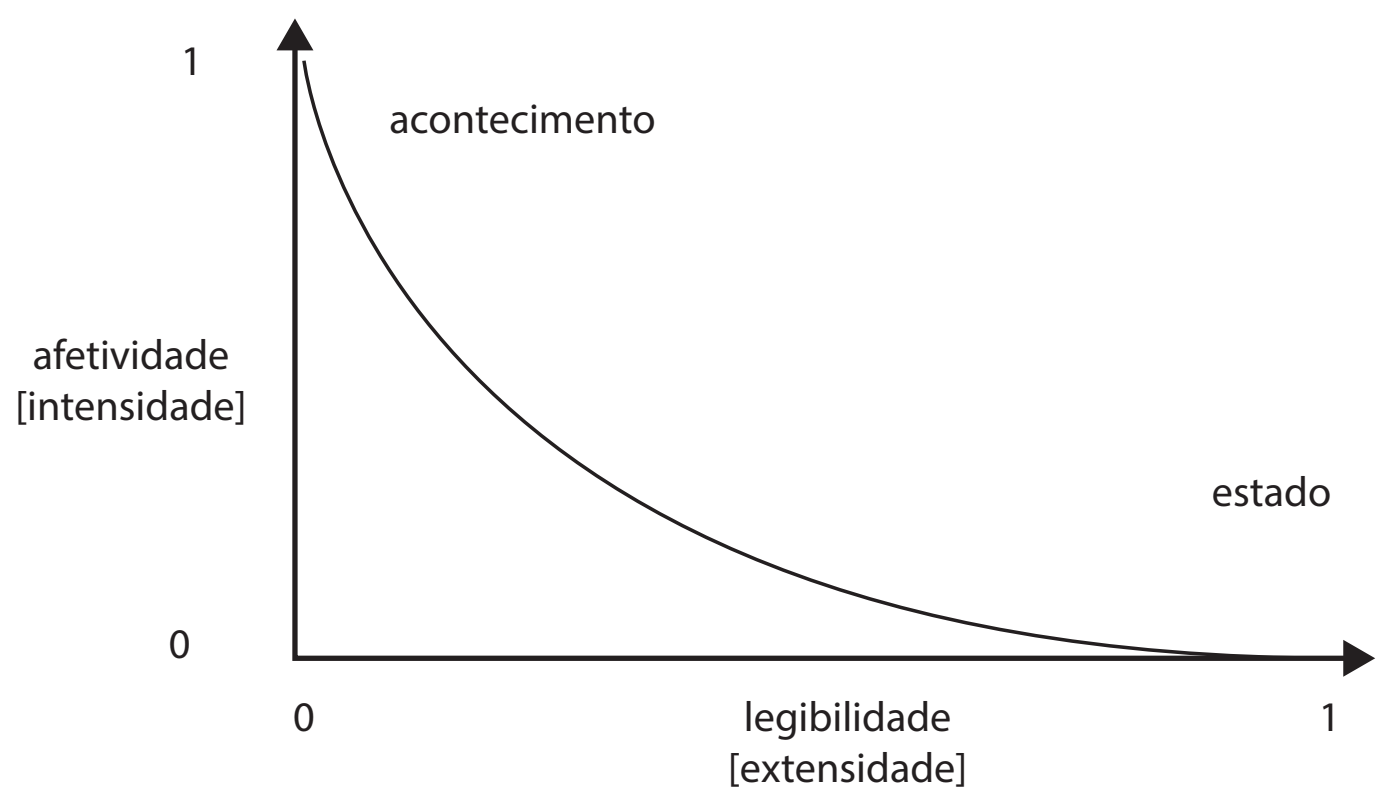

Figura 1: Gráfico tensivo de Zilberberg e Fontanille (2001)

Diz Alexandre Bueno: "a combinação desses dois eixos pode gerar um regime participativo (correlação conversa em que predomina a mistura) ou um regime exclusivo/ de exclusão (a correlação inversa cujo predomínio é da triagem)" (BUENO, 2015, p. 59). Quando se dá a triagem, elementos são separados:

nas semióticas da triagem a circulação de valores é pequena ou nula, e desacelerada pela solução de continuidade colocada entre o exclusivo e o excluído. Nas semióticas da mistura o tempo da circulação é mais rápido numa cultura em que a valência é difusa do que numa outra em que a valência tende a se concentrar num número restrito de grandezas (ZILBERBERG; FONTANILLE, 2001, p. 29).

Por outro lado:

Numa semiótica da mistura o excesso permite, em nome da 'tolerância' da 'abertura', do tão justamente denominado 'pluralismo', passar da 'diversidade' à 'universalidade'; o acento se desloca da diferença (a desigualdade nesse caso) para a semelhança (a igualdade); a falta, que restabelece a 'diversidade' em detrimento da 'universalidade', entra em ação assim que decai o fervor das confraternizações entusiastas, o que como cada um pode sentir, é uma questão de tempo: o ápice não suporta a duração (GREIMAS; FONTANILLE, 1993, p. 34). 
O operador dominante nos discursos do Vem pra rua é a triagem. Nada se faz em nome da tolerância, da diversidade, da universalidade. A questão aqui seria: que lugar a exclusão vislumbrada nos discursos do Vem pra rua concede à participação? Será nulo? Seria precipitado afirmar que sim, embora haja grande homogeneidade, em que, implícita ou explicitamente, são excluídas classes e grupos sociais, como comunistas, homossexuais, população trans, feministas, negros etc. Ou, prosseguindo com Zilberberg e Fontanille (2001, p. 49): "Como, no regime da exclusão, fazer participar os excluídos?". Aqui entram em cena a melhoração e a pejoração, a fim de fazer circular os valores. Num microuniverso dirigido pelos valores de absoluto, a participação é obtida por melhoração (elementos antes excluídos são admitidos). Num microuniverso dirigido pelos valores de universo, a exclusão é obtida por pejoração (elementos maus são retirados). Os valores de absoluto estão no eixo da intensidade, no qual domina o foco. Os de universo, na extensidade, na qual domina a apreensão. Assim:

As transformações restritas esforçam-se para determinar e ajustar os valores médios do mais e do menos. A melhoração suspende a exclusão própria dos valores de absoluto, admitindo no espaço dos valores uma zona participativa; a pejoração suspende a participação, delimitando uma zona exclusiva; em relação à intensidade a melhoração pode passar por uma negação; em relação à extensidade a pejoração desempenha o mesmo papel (ZILBERBERG; FONTANILLE, 2001, p. 49-50).

O exemplo que dão os autores vem de $A$ democracia na América, de Tocqueville, ao comparar a aristocracia com a democracia na América. Ele, apesar de preferir a aristocracia, aponta os efeitos tensivos da democracia:

Compreendo que num Estado democrático [...] a sociedade não será imóvel: mas os movimentos do corpo social poderão nesse caso ser regulamentados e progressivos; se encontramos aí menos brilho que no seio de uma aristocracia, encontramos também menos miséria; as satisfações serão menos extremas e o bem-estar mais geral; as ciências menos amplas e a ignorância mais rara; os sentimentos menos enérgicos e os hábitos mais suaves; notar-se-ão mais vícios e menos crimes (ZILBERBERG; FONTANILLE, 2001, p. 45-46). 
Deixar o sistema aristocrático implica em desistir do ápice dos valores de absoluto e aceitar a difusão, o espalhamento dos valores de universo. A triagem e o fechamento se concentram a partir dos valores de absoluto, como vemos nos discursos do Vem pra rua, enquanto discursos mais democráticos deveriam optar pela mistura e pela abertura, visando a expansão, a participação, a ampliação dos direitos. Isso é o que deveria unificar os programas democráticos, a partir dos valores de universalidade e de diversidade.

\section{O gozo na cultura de consumo}

Falemos rapidamente agora da questão do gozo, com a entrada da psicanálise na discussão. Os laços sociais existem a partir das identificações e do gozo investido nos objetos ligados à cultura de consumo e suas fantasias. Como diz Isleide Fontenelle (2017, p. 181), nenhuma característica foi mais fundamental "para a produção do consumidor do que a ideia de paixões como necessárias ao bem-estar geral". Entre as principais paixões do trajeto de constituição do capitalismo em direção à cultura do consumo estão as paixões ligadas ao egoísmo, a amor sui e à busca do prazer. De fato, o capitalismo da produção intensificou a produção na sua primeira fase (1890-1945), aumentando a quantidade de mercadorias produzidas e diversificando a produção, o que exigiu que aumentasse o consumo, implicando convocar os consumidores, isto é, liberar as pulsões ligadas ao consumo, e as paixões daí decorrentes. Ora, isso contradizia o clima moral do primeiro capitalismo, ligado à ética ascética, de que falava Weber. Assim, o capitalismo teve de incitar ao consumo, o que exigiu uma crescente liberação das paixões. Isso fez com que o supereu freudiano fosse gradativamente substituído pelo supereu lacaniano do gozo, cujo imperativo passou a ser: goze! Tenha prazer! Consuma! Isso coincide também com a pós-contracultura, em que o capitalismo pós-1968 internalizou a crise que apelava para uma maior atenção ao desenvolvimento criativo do eu e do trabalho.

Aspecto importante desse processo está no fato de que a publicidade, de certa forma, absorveu a crítica contracultural. Como diz Fontenelle: foi o próprio 
"movimento contracultural que deu o material criativo necessário para que as agências de publicidade se reinventassem, pois, a partir de então, a publicidade buscou se renovar sob a feição de um discurso crítico, assumindo certa 'estética da resistência'"' (2017, p. 70).

Tudo isso fez com que fosse necessária uma liberação crescente das paixões e uma flexibilização das identidades e do trabalho. É claro que tal se fez na direção de uma maior capitalização do eu, sob a égide do neoliberalismo, como vimos. Ao mesmo tempo, houve uma crise da esquerda, que não respondeu a contento a essas mudanças do capitalismo neoliberal, por um lado, e, por outro, adotou uma política conciliatória com o pemedebismo, que barrou mudanças estruturais na vida do país, já que isso poderia desagradar o capitalismo tupiniquim e o internacional aqui ancorado para prosseguir sua espoliação ampliada da riqueza nacional.

Mas esse giro de supereus, essa internalização da crítica se configura dentro de um processo mais amplo, em que a sociedade se torna uma montagem perversa, segundo Dufour. Se outrora os cristãos apostavam não no amor sui, mas no amor a deus, com o crescimento do capitalismo desde o século XVII, aos poucos, de Pascal a Sade, passando por Mandeville, vai se instaurar um argumento que se propõe a reformar o mundo, contando para isso com o amor próprio, tornando-o esclarecido (DUFOUR, 2013, p. 195). E, para ressaltar os verdadeiros interesses dos demais, é preciso cálculo racional. Segundo Dufour, esse amor próprio esclarecido chama-se amor próprio inofensivo (harmless) em Locke.

O próximo passo nesse longo trajeto, desde o amor próprio como negativo para a sociedade até a construção de uma sociedade liberal em que uma espécie de montagem perversa funciona a céu aberto, é a afirmação de que "não é necessário que os indivíduos sejam virtuosos para que a sociedade o seja" (DUFOUR, 2013, p. 99). E o próximo enunciado dessa série é de Mandeville, que afirma que os vícios privados fazem a virtude pública. Tratava-se da construção de uma nova religião em que se apostava "na liberação das paixões concupiscentes e na constituição 
de um todo superior à soma das partes" (DUFOUR, 2013, p. 103), ou seja, a providência divina não permite que "as coisas se dispersem nos gozos privados, ela produz, pelo contrário, uma ordem 'admirável'" (DUFOUR, 2013, p. 103). Hoje essa ordem admirável se chama neoliberalismo, com a respectiva cultura do consumo. Se antes se criticava a cobiça, a ganância, a paixão pelo dinheiro, em Adam Smith isso vira interesse, conforme nos conta Fontenelle (2017, p. 182). O desenvolvimento do capitalismo só foi possível, portanto, com a liberação das paixões, em particular a do amor próprio. Diz Fontenelle:

A formação do liberalismo e do indivíduo moderno, a partir da liberação das paixões, é fundamental para que possamos entender a lógica contida no consumo como espaço de realização de desejos humanos. [...] Embora a noção de interesse já tivesse feito seu trajeto da política para a economia desde o século XVIII, foi apenas na aurora do século XX que a economia lançou mão dos conhecimentos de duas disciplinas emergentes - psicologia e psicanálise - na busca da compreensão do que move os homens e de como fazer um bom uso desse conhecimento para o desenvolvimento econômico (FONTENELLE, 2017, p. 184).

Esse processo leva à formação de uma sociedade dividida em condomínios em que a política se limita à gestão, e em que cada um está atrás de seus desejos e de seu gozo; para realizá-los, tem de se modalizar a partir dos tecnólogos de discursos. De alguma forma, essa sociedade com vontade de perversão se produz um ambiente em que cada tribo vive sua forma de gozo e não aceita o gozo do outro. Espécie de gozo segregado, como diz Safatle (2017), que é concomitante ao aparecimento de uma patologização de comportamentos pelo DSM.

De um lado, mercado segmentado, tribos segregadas em seus gozos, e de outro, uma normatização ancorada numa rica indústria de medicamentos. Isso se realiza, diz Safatle,

como se a integração dessa diversidade tivesse um preço, o de nos afastar da diferença efetiva. Pois esta tem uma característica perturbadora: ela nos é próxima. A verdadeira diferença é algo insuportavelmente próximo, tão próximo cujo contato pode nos mudar, pode nos contagiar, modificando nossa direção, produzindo em nós metamorfoses (SAFATLE, 2017). 
Diríamos mais: esse contato transformador pode produzir acontecimentos e novos sujeitos. A polarização nos impediu de qualquer fidelidade ao acontecimento de 2013, ou seja, às promessas de despemedebização da política brasileira, e de construção de uma esfera democrática efetiva entre nós. Tal polarização tem a ver com essa batalha de gozos de viver: de um lado alguns gozam com a mistura, de outro alguns gozam com a triagem. Em linhas gerais, o golpe aplicado não se restringiu ao evento específico do impeachment ou à perseguição jurídica de Lula, enquanto muitos outros políticos de outros partidos continuavam em plena atividade no governo e no congresso. O golpe foi mais amplo, no sentido de, contando com a atuação da mídia hegemônica, construir um quadro geral que esvaziava qualquer debate efetivamente político do que realmente ocorria a partir do confronto que a direita criou com o petismo, a fim de desmontá-lo. Conforme Bosco (2017), o lulismo nasceu sob o signo da conciliação, e o impeachment e a polarização constituíram o processo de retomada do poder pela direita. Não que estivesse afastada dele, pois a conciliação significou justamente o recalcamento de "um conjunto enorme de contradições que, como todo recalque, poderia voltar no real (BOSCO, 2017, p. 59). O recalque retornou e desembocou no processo de polarização, pois para amparar o golpe era necessário recorrer a afetos fundamentais naquele momento: o ódio à esquerda, o ódio ao pobre usando aviões, o medo da classe média perder o rumo do eu s/a, o ressentimento de estar espremida (as classes médias mais afluentes) entre pobres e ricos. Sem a emergência desses afetos tristes não seria possível a sustentação cultural do golpe. Ele trouxe à tona afetos historicamente represados e: é o outro, o mortadela sem estilo, que não sabe o rumo do eu s/a, que me impede de gozar, ele sequestra meu gozo. Isso aparece em muitos posts dos movimentos da direita que estudamos. Isso posto, como enfrentar o tema da abertura da perspectiva? Ela vem da ideia de acontecimento e de democracia radical. O acontecimento é a ruptura com um status quo, mas também com o circuito dos afetos (SAFATLE, 2015) que o sustenta, como vimos acima. Fazer a crítica social e midiática significa falar de lutas concretas, dentro da polarização, de modo a desconstrui-la, a minar sua 
sustentação afetiva, em termos de gozo. Só os movimentos sociais concretos podem fazer isso. Em resumo, pensamos a crítica midiática - e a crítica social em termos mais amplos -, considerando o aporte de Butler, via Foucault, ligada às práticas, tendo em conta que a relação com os contextos locais e globais são fundamentais para entender como as marcas e os discursos circulam concretamente em seus embates com outros discursos antagonistas. A polarização se constrói no imaginário e tampona sintomaticamente o real antagonismo. A crítica visa uma atuação frente aos demais discursos e práticas, de modo a fazer ver o antagonismo e a desimaginarizar a polarização ${ }^{4}$. Ela se pensa num quadro emancipatório, considerando emancipação como um universal vazio, não num sentido moderno. É o quadro da democracia radical. Ela tem um movimento profanatório, no sentido de Agamben (2007), e pensa um novo uso da palavra no âmbito das práticas. Em termos de Badiou, ela é acontecimental em dois sentidos: um primeiro, de um novo uso da linguagem para que as decorrências do acontecimento possam ser formuladas pelos sujeitos engajados em seu processo de verdade, e um segundo, de construir novos dispositivos democráticos para que essas consequências sejam implantadas e o circuito dos afetos possa mudar dos afetos tristes para os alegres, acontecimentais, de transformação não ancorada no ressentimento, no medo e no ódio.

O acontecimento permite novas experiências com a palavra, novos usos para ela, para essa palavra que não apenas fala do mundo, mas faz fazer no mundo com sua enunciação. A crítica incide nas práticas atuais de modo a abrir a perspectiva acontecimental, o que não significa planejar, prever, construir o acontecimento, mas abrir perspectiva para criar mundos, outros mundos possíveis com o acontecimento, e para tanto é preciso estar preparado para reconfigurar mundos. Por isso, falamos no aberto da perspectiva. Isso implica em desnaturalizar

O filme $O$ insulto, de Ziad Doueiri, de 2017, trabalha muito bem com esse processo de um circuito dos afetos construído em torno do ódio. No filme, isso começa com um desentendimento entre um cristão e um palestino, que se amplifica em um confronto que mexe com todo o Líbano. A saída ocorre dentro dos tribunais, quando os querelantes começam a historicizar esse ódio e a entender o ponto de vista do outro. Com isso, se complexifica a visão de cada um, se desimaginariza a querela, e cada um pode encarar o outro lado sem ódio. Diríamos que se dá um acontecimento dentro da discussão do tribunal. Os advogados de um e outro lado são pai e filha, o que duplica o conflito. A ideia fundamental aqui é que o ódio tampona os antagonismos, não permitindo que sejam encarados em toda sua complexidade. 
práticas e discursos, desconstruir polarizações e afetos tristes, e em rever o senso comum, mudando os sentidos do consumo e da política (aqui seria o fim do pemedebismo como articulação fisiológica), desarmando as armadilhas do circuito dominante dos afetos. Por isso, a prática da crítica não pode ser abstrata, não pode olhar tudo de cima, mas deve estar engajada nos antagonismos discursivos, deve falar de sua posição concreta no tabuleiro.

A crítica começa como pré-acontecimental, lutando contra discursos antagonistas de modo a abrir a perspectiva para o acontecimento, embora não saibamos como ele será, qual será, quando será. O acontecimento abre a perspectiva desfazendo as linhas de construção e de sustentação de um mundo tornado naturalizado e inanimado. Ele abre perspectiva no sentido de sair do subalterno, do universo da vítima. Há o aberto performativamente inaugurado pelo acontecimento porque ele permite uma emergência, um nascimento. A crítica é o caminho de uma intuição dessa abertura, a de um mundo possível em que muda a máquina antropológica que produz o humano a partir da diferenciação humano/animal5 ${ }^{5}$ A crítica intui como parar essa máquina no antagonismo de suas práticas.

\section{Referências}

AGAMBEN, G. Profanações. São Paulo: Boitempo, 2007.

. O aberto: homem e animal. Rio de Janeiro: Civilização Brasileira, 2013.

ALONSO, A. A política das ruas. Folha de S. Paulo, São Paulo, 25 set. 2016. Ilustríssima. Disponível em: <https://bit.ly/2DX7Mmb>. Acesso em: 10 nov. 2016. um dentro, e o dentro, por sua vez, tampouco é exclusão de um fora" (2013, p. 64). A máquina antropológica dos modernos exclui de si como não humano um já humano, "isolando o não humano no homem", em que um inumano animaliza o humano. 
BADIOU, A. Para uma nova teoria do sujeito. Rio de Janeiro: Relume-Dumará, 1994. O ser e o evento. Rio de Janeiro: Jorge Zahar: UFRJ, 1996.

BOSCO, F. A vítima tem sempre razão? Lutas identitárias e o novo espaço público brasileiro. São Paulo: Todavia, 2017.

BROWN, W. Neoliberalism and the economization of rights. In: LAFONT, C.; DEUTSCHER, P. Critical theory in critical times: transforming the global political and economic order. New York: Columbia University Press, 2017. p. 91-112.

BUENO, A. M. Para uma gramática da intolerância. Entremeios: revista de estudos do discurso, v. 10, p. 57-68, jan./jun. 2015. Disponível em: <https://bit.ly/2E2oNvk>. Acesso em: 5 jan. 2018.

BUTLER, J. What is critique? In: SALIH, S.; BUTLER, J. Judith Butler reader. London: Blackwell, 2005. p. 302-322.

DUFOUR, D.-R. A cidade perversa. Rio de Janeiro: Civilização brasileira, 2013.

FONTENELLE, I. A resignificação da crise ambiental pela mídia de negócios: responsabilidade empresarial e redenção pelo consumo. Revista Galáxia, São Paulo, v. 13, n. 26, p. 135-147, 2013.

. Cultura do consumo. São Paulo: FGV, 2017.

FOUCAULT, M. O nascimento da biopolítica. São Paulo: Martins Fontes, 2008.

GREIMAS, A. J.; FONTANILLE, J. Semiótica das paixões: dos estados de coisas aos estados de alma. São Paulo: Ática, 1993. 
HOWARTH, D. ; STAVRAKAKIS, Y. Introducing discourse theory and political analysis. In: HOWARTH, D.; NORVAL, A. ; STAVRAKAKIS, Y. Discourse theory and political analysis: identities, hegemonies and social change. Nova Iorque: Manchester U.P., 2000. p. 1-18.

LACLAU, E. A razão populista. São Paulo: Três Estrelas, 2013. . Hegemonia e estratégia socialista. São Paulo: Intermeios, 2015.

LAZZARATO, M. ; ALLIEZ, É. Guerres et capital. Paris: Amsterdam, 2016. Disponível em: <https://bit.ly/2GxTu0U>. Acesso em: 12 fev. 2018.

NASIO, J. D. Cinco lições sobre a teoria de Jacques Lacan. Rio de Janeiro: Zahar, 1993.

PRADO, J. L. A. Regime de visibilidade em revistas. São Paulo: PUC-SP, 2011. 1 DVD.

. Convocações biopolíticas dos dispositivos comunicacionais. São Paulo: Educ, 2013a.

. Política do acontecimento. Revista Famecos, Porto Alegre, v. 20, n. 2, p. 495-520, maio/ago. 2013b.

- Comunicação como espistemologia do sul: do reconhecimento à emergência do acontecimento. Matrizes, São Paulo, v. 9, n. 2, p. 109-125, jul./dez. 2015.

A política do performativo em Butler. In: GREINER, C. (Org.). Leituras de Judith Butler. São Paulo: Annablume, 2016a. p. 15-35. 
Comunicação e reinvenção acontecimental da política. In: JESUS, E.; JANOTTI JUNIOR, J.; TRINDADE, E. Reinvenção comunicacional da política. Brasília: Compós, 2016b. p. 15-30.

. Da antipolítica ao acontecimento: o anarquismo dos corpos acontecimentais. Comunicação, mídia e consumo, São Paulo, v. 14, p. 10-30, jan./abr. 2017a. Disponível em: <https://bit.ly/2GE4k5C>. Acesso em: 27 mar. 2018.

Decifrando os pontos sintomáticos do capitalismo comunicacional. In: PRADO, J. L. A.; PRATES, V. (Org.). Sintoma e fantasia no capitalismo comunicacional. São Paulo: Estação das Letras e Cores, 2017b. v. 1, p. 13-34.

- Reconhecimento tenso, acontecimento inaugural: na direção de outra comunicação. Revista E-Compós, Brasília, v. 20, p. 1-15, 2017c.

Afetos em confronto: quem vai para a rua? In: FREIRE FILHO, J. (Org.) Afetos, emoções e sentimentos: horizontes de pesquisa em comunicação. 2018. No prelo.

PRADO, J. L. A.; CAZELOTO, E. Valor e comunicação no capitalismo globalizado. Revista E-Compós, Brasília, v. 6, ago. 2006. Disponível em: <https://bit. ly/2J03RbU>. Acesso em: 15 set. 2012.

As tecnologias digitais num futuro despotencializado. In: PRADO, J. L. A.; PRATES, V. (Org.) Sintoma e fantasia no capitalismo comunicacional. São Paulo: Estação das Letras e Cores, 2017. v. 1, p. 105-129.

PRADO, J. L. A.; PRATES, V. Sobre a sustentabiliade como fantasia liberal-capitalista: do tampão verde à ecologia sem natureza. Revista Famecos, Porto Alegre, v. 22, p. 1-14, 2015. Disponível em: <https://bit.ly/2E0ptBk>. Acesso em: 27 mar. 2018. 
O significante "povo brasileiro" na crise política do impeachment de Dilma Rousseff. In: CONFERÊNCIA INTERNACIONAL PATOLOGIAS E DISFUNÇÕES DA DEMOCRACIA, 2017, Covilhã. Anais... Covilhã, Universidade Beira Interior, 2017a. . (Org.) Sintoma e fantasia no capitalismo comunicacional. São Paulo: Estação das Letras e Cores, 2017b.

PRADO, J. L. A. et al. A invenção do Mesmo e do Outro na mídia semanal. São Paulo: PUC-SP, 2008. 1 DVD.

SAFATLE, V. O circuito dos afetos. São Paulo: Cosac Naify, 2015. . Descobrir outras formas de gozo pode quebrar nossos tabus e dogmas. Folha de S. Paulo, São Paulo, 15 set. 2017. Ilustrada. Disponível em: <https:// bit.ly/2pJl01F>. Acesso em: 12 fev. 2018.

SANTOS, B. S. S. A gramática do tempo. São Paulo: Cortêz, 2006. Reinventar a teoria crítica. São Paulo: Boitempo, 2007.

ZILBERBERG, C. As condições semióticas da mestiçagem. In: CAÑIZAL, E. P.; CAETANO, K. E. (Org.) Olhar à deriva: mídia, significação e cultura. São Paulo: Annablume, 2004. p. 69-101.

. Elementos de semiótica tensiva. São Paulo: Ateliê, 2011.

ZILBERBERG, C.; FONTANILLE, J. Tensão e significação. São Paulo: Humanitas, 2001.

ŽIŽEK, S. Menos que nada. São Paulo: Boitempo, 2013. 
Event: philosophical journey through a concept. Londres: Melville House, 2014.

ZUPANCIC, A. What is sex. London: MIT Press Cambridge, 2017.

submetido em: 12 fev. 2018 | aprovado em: 22 mar. 2018 